tively engaged in defining an appropriate federal role to contribute toward a solution. But we all acknowledge that Congress cannot solve the problem alone-nor can any other single agent. The enormity of the problem and the costs associated with developing and implementing programs to preserve brittle books dictate a responsibility within every sector of the nation. Therefore, while the proposed White House Conference on Library and Information Services will not "solve" the brittle book problem we consider here today, it would provide a forum to continue to raise the level of understanding about the scope and seriousness of the challenge we all face. We appreciate the support members of the Subcommittee showed in the past for the Conference and hope we may count on that support continuing again this year.
To sum up: We recognize the urgency and magnitude of the library materials preservation problem. We have a plan whereby decisions can be made as to what material needs preservation and in what priority. We have a rough idea of the costs involved. We accept the concept of reasonable cost sharing. And we are rather well equipped - except for the lack of a federal policy of commitment to help resolve the problem of brittle library materials, and except for sufficient funding.

To improve access to cultural resources and safeguard our own future, the Congress must act, providing leadership and help with financial aid. On behalf of the Association of Research Libraries and the American Library Association, I request your support.

\title{
Stalking the elusive grey literature
}

\author{
By Peter Allison \\ Head, Tamiment Institute Library \\ New York University
}

\section{A neglected category of materials with very special problems.}

\begin{abstract}
W e call it grey or fugitive literature because it eludes easy definition. It's all around us, but it is seldom central to our concerns as librarians or information professionals. You can't buy it in bookstores and most of it isn't marketed very actively to libraries. Although most grey literature is aimed at a non-academic audience, there is an active strain of grey literature within the scholarly communication process. Special libraries have always collected grey literature and used it effectively within a mediated environment. Larger, centralized academic libraries have found it problematic. Changes in the reward system within higher education and
\end{abstract}

greater emphasis on the training of professionals and practitioners have increased interest in this sort of material. At the same time, traditional solutions that have provided access and bibliographic control to large bodies of grey literature are being called into question.

Most grey literature does not contribute to the growth of fundamental knowledge. It applies existing knowledge to real world problems. It digests and summarizes knowledge for busy decision makers. It advocates particular policy choices based on a combination of knowledge and group interest. It advertises the accomplishments, collec- 
tions and research capabilities of particular organizations. It assesses feasibility and anticipates impacts. It aggregates statistics, compiles inventories and issues standards, guidelines, plans, and prognostications.

Almost every field has some sort of grey literature. In the performing arts almost all written texts-scripts, screenplays, scores, actor's editions-have a fugitive aspect. Exhibit catalogs, maps, and architects plans also qualify. The largest amount of grey literature, however, is generated by disciplines and professions with a large audience of educated practitioners working outside the academy. Business, criminal justice, development economics, engineering, health care, labor relations, and public administration are just some of the subjects awash with grey literature. Our own fields, higher education and librarianship, are similarly inundated.

As the training of practitioners and professionals of all sorts has become a larger part of the higher education enterprise, the demand for grey literature has accelerated. For several good reasons, libraries have been reluctant to respond. Because this literature is not actively marketed to libraries, it is expensive to search out and often frustratingly difficult to acquire. Consultants and contractors prepare reports for paying clients who generally control any subsequent distribution. Work funded by government and foundation grants is often haphazardly distributed because the producers lack marketing expertise and economic incentive. At a different extreme, the demand for certain kinds of market research and executive intelligence services permits their producers to price such products beyond the reach of libraries.

Although grey literature should not be confused with ephemera, very little of it can approximate Ezra Pound's criterion for poetry, "news that stays news." Because it addresses practical problems and contemporary issues, its use value decreases sharply with age. Speed of acquisition is consequently crucial. Since very few libraries acquire and formally catalog this literature, those that wish to do so may discover that even timely acquisitions disappear into cataloging backlogs because there is "no copy in the system."

Most grey literature is additionally decidedly insubstantial by library standards. It is often deliberately short because it must compete for the attention of busy people. It often costs more to bind than to buy and is easily misplaced in open stack libraries because call numbers cannot be placed on thin spines.

The working paper and the dissertation have traditionally been scholarly forms of grey literature. Librarians have generally declined to collect these preliminary statements, preferring to await their revised appearance as journal articles and scholarly monographs. Current circumstances and practices, however, have eroded the logic of this position. As more Ph.D's go into non-academic ca-

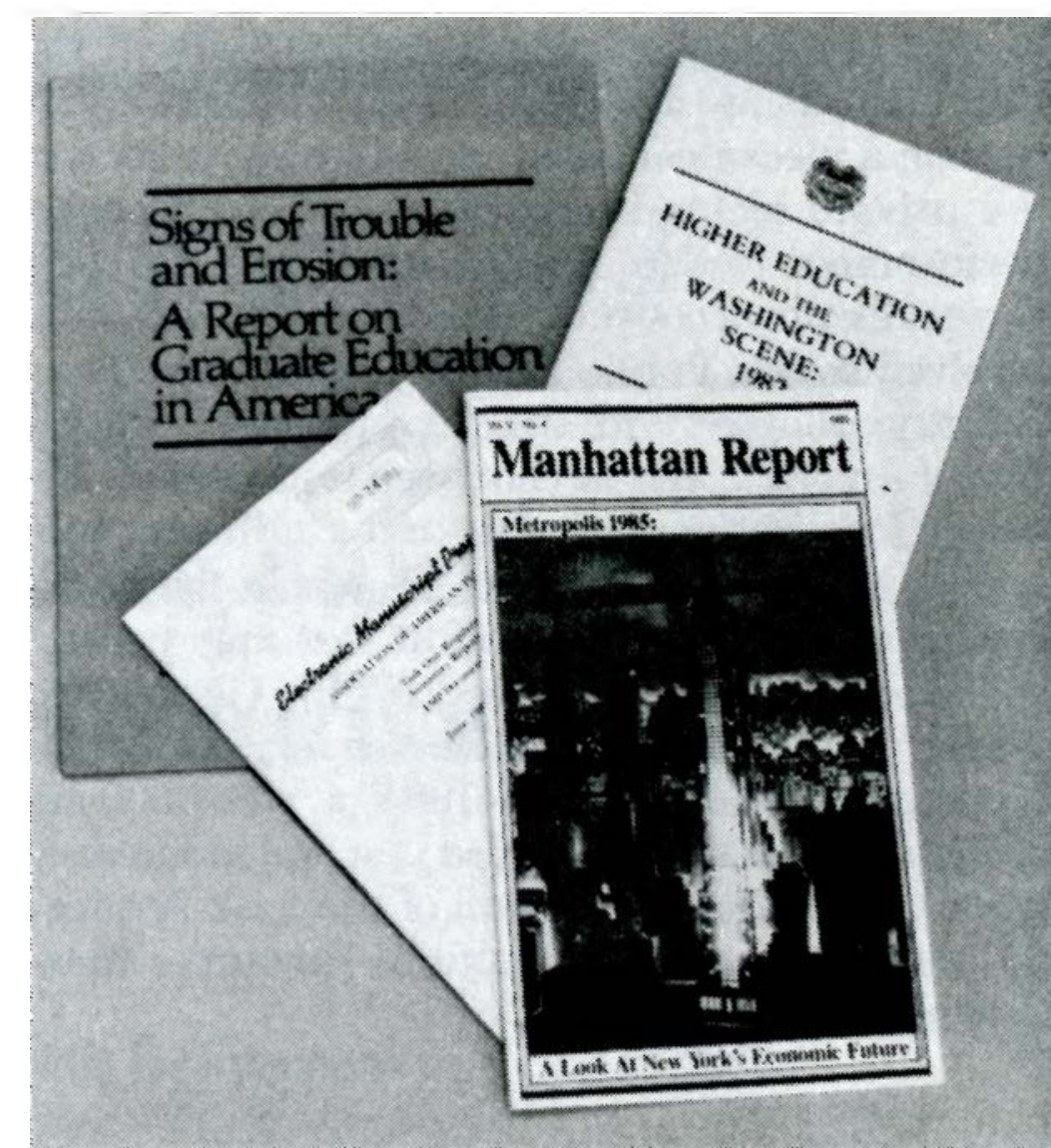

Grey literature in the social sciences (courtesy of New York University).

reers, significant dissertations are not always revised for publication. For different reasons, working papers are no longer predictably recast as journal articles. In an environment that stresses the pursuit of external funds, what was once a subsidiary purpose behind a working paper seriesadvertising the work being done at a particular research center-now appears to be both primary and sufficient in many cases.

Most librarians commonly associate grey literature with technical reports, a poorly comprehended genre of material generally consigned to the Engineering Library or the netherworld of Government Documents. As the largest funder of scientific, technical and social science research, the federal government is indeed a prime sponsor of grey literature. More importantly, it has sustained a system of information clearinghouses that have assured continuous access to vast numbers of publications and provided both print and online indexing to these databases.

In the past the federal government, through the National Technical Information System (NTIS), ERIC, the Department of Energy's Technical Information Center and numerous other agency sponsored databases, kept a great deal of grey literature perpetually available. We cannot be sure that this will continue to be the case. The privatization of NTIS remains an avowed goal of the current administration and rumors persist about a planned "reexamination" of the ERIC system.

Since the importance of grey literature to our users is increasing, we need to concern ourselves with any developments that affect its availability and bibliographic control. As our library holdings are increasingly represented in automated form, collections that cannot easily be converted to MARC 
format are marginalized. If we can't afford the time and expense involved in acquiring grey literature on a piecemeal basis, we will have to look to the private sector for assistance. Unfortunately performance to date isn't encouraging. A Health Care microform collection based on grey literature received by the Public Health Service's Parklawn Library collapsed with the Microfilming Corporation of America, and has not been resuscitated. Research Publications failed to find a sufficient subscriber base for its proposed "Papers in the Policy Sciences." In a marketing effort that may presage the practices of a privatized NTIS, ChadwyckHealey is now offering "Research Studies by the National Park Service 1935-1984" as a $\$ 24,500 \mathrm{mi}-$ crofiche set, atavistically tied, for the moment at least, to a microform edition of the Park Service's in-house database, the Cultural Resources Management Bibliography.
The private sector cannot be expected to solve our problems for us if we don't communicate with them. If we want certain bodies of grey literature organized, indexed and shipped to us in timely microform installments, we need to develop our priorities and pitch the idea to potential vendors. If we want such collections to include machinereadable records for our online catalogs, we need to tell our network systems people that this sort of cooperation is a priority. Lastly, we have to be prepared to pay for the products we want.

Editor's Note: At the ALA Annual Conference in San Francisco this June, ACRL's Law and Political Science Section and SRRT's Alternatives in Print Task Force will co-sponsor a program on grey literature in the public policy process. See page 269 for details.

\section{The terminal professional degree: What does it mean for you?}

Do you have a terminal degree? Do you want one? Do you care? On Sunday, June 28, 1987, from 8:00 to 10:00 p.m. at the ALA Annual Conference in San Francisco, the ACRL Academic Status Committee will sponsor an open hearing on the terminal professional degree for academic librarians.

Some consider this issue to be a pain that will not go away. Others simply do not care about the matter because it does not seem to affect them. But what are the issues which drive the questions about a terminal degree?

The master's degree in library science has been shaped typically as the postbaccalaureate degree conferred upon candidates following one year of graduate study. It is viewed by many in the field as the terminal professional degree, although others view it as a stepping-stone to the doctorate and a foundation for further enrichment in the field.

The revised ACRL statement as it is being proposed by the Academic Status Committee states:

"The Master's degree from an academic program accredited by the American Library Association is the appropriate terminal professional degree for academic librarians."

These 22 words focus the debate, but the issue of the terminal degree is only one concern raised by the statement. Almost every word could be debated at the hearing even though the statement continues to recognize the master's degree from an ALA-accredited program and it establishes the degree as the terminal professional degree. Through the Committee's work, ACRL is in the process of adopting this statement as a policy of the Division. It should be a members' statement, not the Com- mittee's or the Division's. It should reflect what the membership wants as the reality of the profession.

After the hearing, the Academic Status Committee will take appropriate action to forward the statement to the ACRL Board of Directors for approval and adoption.

If you care about your profession and the impact of the "terminal degree" and your status, attend the hearing and state your views. If you will not be attending the Annual Conference in San Francisco, please send your comments to the Committee chair, Keith Cottam, 1167 Inca Drive, Laramie, WY 82070 , or call him at the University of Wyoming at (307) 766-3279.

\section{Borrowing special collections materials for exhibition}

At its 1987 Midwinter Meeting the RBMS Executive Committee accepted a document prepared by the Ad Hoc Committee for Developing Guidelines for Borrowing Special Collection Materials for Exhibition. The document, "Information for Prospective Borrowers," was published in the Spring 1987 issue of Rare Books \& Manuscripts Librarianship, pp.27-34, and will be submitted to the ACRL Board of Directors for final adoption. Anyone wishing to comment on the document may contact: Ellen S. Dunlap, Chair, Rosenbach Museum \& Library, 2010 DeLancey Place, Philadelphia, PA 19103. 